\title{
THE PATH OF THE SOCIAL ENTREPRENEUR: A NARRATIVE ANALYSIS APPROACH
}

Fredric Kropp, Monterey Institute of International Studies, USA Ronit Yitshaki, Bar-Ilan University, Israel

Clayton T. Snyder, EcoMedia - CBS, USA

\begin{abstract}
Social bricoleurs are typically small-scale local social entrepreneurs who focus on unmet social needs for disadvantaged groups that have limited capacity to help themselves. Little is known about the motivations social entrepreneurs who are important change agents in solving social problems. The changing role of government in solving social problems and the subsequent expansive growth of social entrepreneurship creates the need for a better understanding of the characteristics and motivations of social entrepreneurs. A better understanding of the motivations and processes of social entrepreneurs can facilitate their effectiveness in solving social problems.
\end{abstract}

Using the life story method we examine 43 social bricoleurs from 9 countries. The life stories method is an inductive approach, reflective in nature, which examines motivations and gives meaning to actions and intentions. Our examination of their life stories identifies two general categories of motivations. The first category is pull factors including long-standing awareness of social injustice and formative life experiences that identified social inequalities. The second category is push factors, relating to a lack or meaning or job dissatisfaction. Preliminary analysis indicates that social bricoleurs motivations are similar in different cultures.

Social entrepreneurs also referred to personal evolution of their self-identity in the process of being social entrepreneurs. Motivations are often emotional and based on life events. Similar to commercial entrepreneurs, social entrepreneurs are able to identify opportunities rather than problems. Their social awareness enables social entrepreneurs to create and exploit social opportunities. In addition, when referring to the present conditions or future expectations, social bricoleurs often look to scalability of their efforts.

References available upon request 